\title{
Achieving Sustainable Development Goals Using Big Data Analysis
}

\author{
Nashrah $^{1}$, Ihtiram Raza Khan ${ }^{2}$, Hadiba Khanam ${ }^{3}$ \\ \{Nashrahfatima3@gmail.com,iraza@jamiahamdard.ac.in,Hadibakhan4@gmail.com\} \\ Jamia Hamdard, New Delhi , India
}

\begin{abstract}
India is having great period of prosperity and importance of sustainable development is increasing day by day. Two thirds of countries economic output is generated from cities, as a result of which large number of Indians have started migrating to urban areas to find employment. By 2030, it is predicted that about sixty eight cities of India will have more than one million inhabitants and six megacities with more than ten million each .Rapid growth in cities give rise to many challenges like limited access to sufficient health care and not enough power supply. City development and planning is crucial for sustainable development in order to meet the challenges of continued growth without destroying the environment and social harmony.
\end{abstract}

Keywords: Big data analytics, Sustainable development, VAMPIRE, Sustainable development goals Sustainable development solution network. 


\section{Literature Review}

The data revolution is deriving new ways in real world data for better insights and actions towards achieving the sustainable development goals. Hundreds of projects are using big data tools and technologies to help government reimagine solutions to strengthen policy and improve service delivery. The data produced from mobile phones to better connect urban residents to jobs, services and economic opportunities. We are supporting the countries to work with local governments, GPS location data from taxies to reduce traffic congestions and improve services like emergency. ${ }^{1}[1]$

India is supporting to use night time satellite imagery to monitor and ensure the electrification of rural areas. Robust data analysis is possible because we use both traditional data and big data. Big data brings new opportunities but also presents a set of unique challenges. The World Bank is a valuable partner in build, boost and broker capabilities that government needs to put big data in action for the sustainable development goals. Our expertise in traditional data is essential to validate insights data from big data sources and develop new standards. Our experience developing new data norms and standards can help address security, ethics and privacy concerns. ${ }^{2}[2]$ Our technical and sector expertise ensures that the solutions are relevant, robust and customized to local contexts. Our world class knowledge and learning can support capacity building and local integration with its solutions.

\section{Introduction}

The idea of sustainable development emerged in late 1980's with response to the worlds growing social and environmental problems. With globalization the inequality gap between rich and poor countries is widening every day and projection for population growth is alarming. The term sustainable development was officially defined in 1987. Sustainable development is the development that meets the needs of present generation without compromising the needs of future generation. This concept appeared with publication of the Brundtland Report. Sustainable development means growth must be accomplished with nature and human kind. Sustainable development creates values. Upgrading production tools and by using less energy and water is good for environment. Offering eco designed products and packaging is used is just necessary it saves material and reduces shipping costs. Paying attention to employees, improving quality of life at work and helping to developing their

\footnotetext{
${ }^{1} \mathrm{~J}$. Wanner and C. Janiesch, "Big Data Analytics in sustainablity reports : An analysis based on the perceived credibility of corporate published information," CrossMark, Germany, 2019.

${ }^{2}$ O. Odhiambo and F. Umar, "Harnessing Big Data for sustainable development in Nigeria," Journal of Sustainable Development, vol. 12, no. Achieving Sustainable Development Goals by 2030, p. 13, 2019
} 
skills. ${ }^{3}[3]$

\subsection{Pillars of Sustainable Development}

Sustainable development means we need to keep three things in mind: Social progress, economic development and climate environment. These factors are also known as pillars of sustainable development. These factors have a long term effect on humans.

Three pillars of sustainable development are explained below:

Economic Pillar: Economy pillar is also referred to as profit. In economy pillar, sustainability means to use a set of resources in an efficient and responsible way that results in long-term benefits. Sometimes, this pillar is also known as governance pillar.

Social Pillar: Social pillar refers to public policies that support social issues that are related to our well-being including healthcare and education.

Environmental Pillar: Environmental sustainability happens as procedures, structures, and practices minimize an organization's assets, goods, and operations ' environmental impact. ${ }^{4}[4]$

${ }^{3}$ B. J. Bhat, "Sustainable development efforts in India- A Study," in Globalbizresearch, Bangkok , Thialand, 2015.

${ }^{4}$ A. Beattie, Interviewee, Three pillars of corporate sustainability. [Interview]. 16 June 2019 


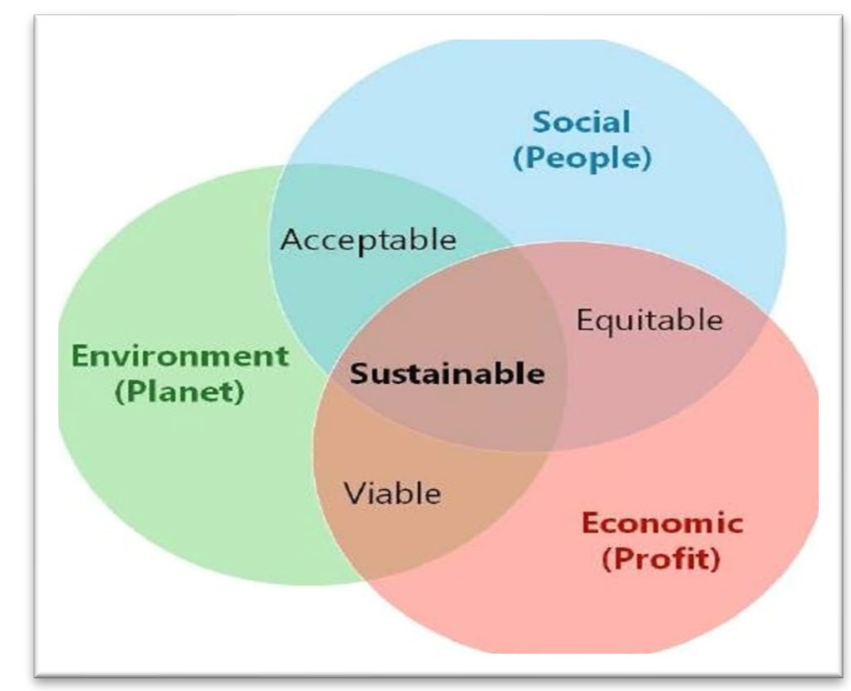

Figure 1 : Pillars of Sustainable Development

\section{Use of Big Data in Sustainable Development}

Big data is used in all sorts of businesses, non-profitable organizations and other groups to improve their understanding of certain topics and to improve their practices in that field. Today a global data revolution is unfolding all over the world. As people communicate through mobile devices, on social media or by surfing on the internet they produce vast amounts of digital data once aggregated and analyzed to protect the privacy of individuals and groups these new sources of data can be harnessed for public good. A task team has already been set up by United Nations to explore the usage of big data in achieving sustainable Development Goals. In a survey the task team found out that big data projects mostly focused on the "NO POVERTY" goal and the most common data source that was used was mobile data. UN Global pulse is an initiative of the united nation secretory general. It's a post member state and the UN system in using this digital data in order to enable more inclusive and responsive programs and policies.

There are several Global pulse projects that show how the new digital data can be used to facilitate the achievement of sustainable development goals. Analyzing public social media content can help the policy makers understand in real time what issues people care about. Data derived from aggregated mobile phone usage can be valuable in understanding and predicting the spread of a disease. Even people who are not connected to the internet are still producers of big data for example a letter sent to the post office generated data footprint. Researchers have found links between the letter flow and economic indicator such as GDP such information can provide a global picture of economic trends, poverty and resilience.Forest fire 
continues to occur around the world often causing health problems and environmental destruction. Analysing social media, online video and content from public radio broadcast can give real time information on the location of fire hotspots and the need of effected population. This can enable an authority to respond faster and more effectively to the situations on the ground. The amount of data produced globally is growing double every year. Harnessing this data revolution is a key for achieving and monitoring progress towards the sustainable development goals. The public sector, the private sector and the civil society must all work together to achieve a future in which big data is used responsibly as a public good that no one is left behind. ${ }^{5}$ [5] There are many potential uses for big data that are related to the sustainable development goals. Data can be used in, any ways to improve our understanding in the progress towards sustainable development goals and to determinehow effectively we can meet those targets and ensure their accountability.

${ }^{5}$ E. Folk, Interviewee, Use of Big Data in achieving Sustainable development Goals. [Interview]. 1 July 2020 


\section{Challenges}

There is abundance of opportunities related to big data but there are number of challenges and risks also. Some challenges are data organization which includes collecting, storing and analyzing data and other challenge is privacy of data that are collected from multiple sources.

- Collecting and Storing Data: For storing, collecting and analyzing large amount of data there is a special need of advance technology and infrastructure that can be expensive. Collecting and storing data can itself become challenging. In a survey a team observes that a low-income country responds less than high-income countries.

- Privacy: Privacy is also a concern in collecting and storing data. It is necessary that the process should respect the rights of whom data is collected. Privacy is not always guaranteed by removing the sensitive data because identification of people could be done combining information from multiple data sets.

- Identify boundaries to economic growth: Identifying boundaries means a lot of things depend on technological decoupling and to what extends it is possible that what we would measure or call economic growth or economic progress without requiring more primary resource use.

- Ensuring proper childhood development: This challenge is one of the most effective or efficient investments to ensure physical development of young children. Some scientists also say that there is no way that those children are going to get the locally produced food. ${ }^{6}[6]$

\footnotetext{
${ }^{6}$ A. Kharrazi, H. Qin and Y. Zhang, "Urban Big Data \& Sustainable Development Goals : Challenges \& opportunities," MDPI, China, 2016
} 


\section{Solutions}

Sustainable development solution network is a global independent network that globalizes its scientific and technical expertise from academic, civil society and the private sector to achieve sustainable development. This is achieved by its four dimensions and they are as follows:

- Economic development including the eradication of extreme poverty

- Social inclusion

- Environmental sustainability

- Good governance including peace and security

In this context the sustainable development solution network promotes the pursuit of the 17 sustainable development goals of the United Nations general assembly and approved by the 193 member states in September 2015. In order to achieve its mission the SDSN activity focuses on applied research on practical solution for sustainable development, promotion and implementation of $\mathrm{SDG}^{\text {ee }} \mathrm{s}$, education for sustainable development including massive open online courses ${ }^{7}$. [7]

VAMPIRE: Government of Indonesia and United Nations is working on various big data projects. "e Vulnerability analysis monitoring platform for impact of regional events (VAMPIRE) is one of them. VAMPIRE utilizes several types of data including population, rainfall anomaly, and household food security. This platform uses three layers of databases. The Layers are explained below:

- Baseline Layer: This layer shows the percentage and distribution of poor, agriculture-dependent people and the communities at a risk of food security.

- Climate Layer: This layer shows the rainfall quantity in an era related to longstanding averages at that time of the year and it also shows plant life health to understand the extinct of agricultural drought.

\footnotetext{
${ }^{7}$ A. Bhamra, H. Shauker and Z. Niazi, "Achieving Sustainable development in India- A Study of finacial Requirements \& Gaps,” Ministry of Environment, Forest \& Climate Change, New Delhi, India, 2015
} 
- Impact Layer: This layer shows correlations between the Climate and Baseline Layers and identifies priority areas for support programs based on vulnerability ${ }^{8} \cdot[8]$

${ }^{8}$ VAMPIRE : Data for Social Good Pulse Lab Jakarta Case Study, 2018. 


\section{Conclusion}

Sustainable development is not an issue of conclusion. It should be an on-going process for every economy on the globe. Factors like Human Capital development, innovation promotion and development of infrastructure and institution will always contribute in making sustainable development in present scenario. Everyone understands the need to grow their economies but not everyone take into account the negatives that an unbalanced economic growth can harm the environment it's time to change that by taking a different look at the world. Sustainable development goals will help us to do that. Sustainable development is about improving the life of everyone everywhere and achieving all those things together but it is also about the details that means we want economies growing companies to get people to have decent jobs. ${ }^{9}$ [9]We want to create new technologies but not by harming the environment. We want everyone to have access to nutritious food, affordable education for everybody not too few. In true sense sustainable development is all about the dedicated and undivided efforts of every citizen of every country on the planet earth. We just have to think new ways .All the factors must work together and that is what sustainable development is.

\section{References}

[1] J. Wanner and C. Janiesch, "Big Data Analytics in sustainablity reports : An analysis based on the perceived credibility of corporate published information," CrossMark, Germany, 2019.

[2] O. Odhiambo and F. Umar, "Harnessing Big Data for sustainable development in Nigeria," Journal of Sustainable Development, vol. 12, no. Achieving Sustainable Development Goals by 2030, p. 13, 2019.

[3] B. J. Bhat, "Sustainable development efforts in India- A Study," in Globalbizresearch, Bangkok, Thialand, 2015.

[4] A. Beattie, Interviewee, Three pillars of corporate sustainability. [Interview]. 16 June 2019.

[5] E. Folk, Interviewee, Use of Big Data in achieving Sustainable development Goals. [Interview]. 1 July 2020.

[6] A. Kharrazi, H. Qin and Y. Zhang, "Urban Big Data \& Sustainable Development Goals : Challenges \& opportunities," MDPI, China, 2016.

[7] A. Bhamra, H. Shauker and Z. Niazi, "Achieving Sustainable development in India- A Study of finacial Requirements \& Gaps," Ministry of Environment , Forest \& Climate Change, New Delhi, India, 2015.

[8] VAMPIRE : Data for Social Good Pulse Lab Jakarta Case Study, 2018.

[9] K. K. Gupta and S. Chirayath, "Sustainable Development in India - A Perspective," GALAXY International Interdisciplinary Research Journal, vol. 1 (2), no. Achieving Sustainable Development Goals by 2030, p. 8, 2013.

\footnotetext{
${ }^{9}$ K. K. Gupta and S. Chirayath, "Sustainable Development in India - A Perspective," GALAXY International Interdisciplinary Research Journal, vol. 1 (2), no. Achieving Sustainable Development Goals by 2030, p. 8, 2013.
} 